\title{
Sistem Informasi Penerimaan Siswa Baru Dengan Model Waterfall Pada Yayasan As-Sabiquun
}

\author{
Dewi Yuliandari ${ }^{*}$, Diah Wijayanti ${ }^{1}$, Kurniawan $^{1}$, Yuli Komalasari ${ }^{2}$ \\ ${ }^{1}$ Sistem Informasi; Universitas Bina Sarana Informatika; Jl. Raya Cibarusah No. 168 Cikarang \\ Square, Cikarang Selatan, Bekasi, Jawa Barat, 17550, Telp. 021-89845468, Fax. 021- \\ 89845467, e-mail: dewi.dwy@bsi.ac.id, diah.dhw@bsi.ac.id, kurniawan.bekasi@yahoo.com, \\ ${ }^{2}$ Teknik Informatika; Universitas Bina Sarana Informatika; Jl. Raya Cibarusah No. 168 Cikarang \\ Square, Cikarang Selatan, Bekasi, Jawa Barat, 17550, Telp. 021-89845468, Fax. 021- \\ 89845467, e-mail: yuli.yks@bsi.ac.id \\ * Korespondensi: e-mail: dewi.dwy@bsi.ac.id
} Diterima: 30 April 2020; Review: 7 Mei 2020; Disetujui: 15 Mei 2020

Cara sitasi: Yuliandari Dewi, Wijayanti Diah, Kurniawan, Komalasari Yuli. 2020. Sistem Informasi Penerimaan Siswa Baru Dengan Model Waterfall Pada Yayasan As-Sabiquun. Bina Insani ICT Journal. Vol 7 (1) : 83-94

\begin{abstract}
Abstrak: Pendidikan adalah hal yang sangat berpengaruh terhadap perkembangan suatu bangsa, pada era sekarang ini pendidikan sudah harus bisa menyesuaikan dengan perkembangan teknologi yang ada dengan mengagas kurikulum baru yaitu kurikulum 2013 berbasis komputasi. Pada Sekolah As-Sabiquun belum ada sistem yang terkomputerisasi dalam hal peneriman siswa baru sehingga sering terjadi kerangkapan data, karena sebab itu sekolah As-Sabiquun sangat membutuhkan adanya sistem informasi yang menunjang dalam proses penerimaan siswa baru. Dengan demikian sudah sewajarnya jika perombakan terjadi pada sistem sekolah dengan menggunakan teknologi terkomputerisasi salah satunya adalah untuk masalah penerimaan siswa baru pada sekolah As-Sabiquun. Metode yang digunakan dalam pengembangan sistem ini adalah dengan menggunakan metode waterfall. Hasil dari penelitian ini adalah berupa sistem informasi penerimaan siswa baru berbasis web yang diharapkan dapat mempermudah proses pengolahan data siswa pada sekolah As-Sabiquun.
\end{abstract}

Kata kunci: sistem informasi ,sistem penerimaan siswa baru, waterfall

Abstract: Education is a very influential thing on the development of a nation, in this current era education must be able to adjust to the development of existing technology by examining the new curriculum, namely the 2013 curriculum based on computing. In the As-Sabiquun School there is no computerized system in terms of the acceptance of new students so that duplication of data often occurs, because of that the As-Sabiquun school is in need of an information system that supports the admission process of new students. Thus it is natural that an overhaul occurs in the school system using computerized technology one of which is for the problem of admission of new students to the As-Sabiquun school. The method used in the development of this system is to use the waterfall method. The results of this study are in the form of a webbased admission information system that is expected to facilitate the processing of student data at the As-Sabiquun school.

Keywords: information system, new student admission system, waterfall

\section{Pendahuluan}

Sekolah adalah salah satu lembaga terpenting dalam pembangunan pendidikan suatu bangsa, kuat atau lemahnya pendidikan menentukan kualitas generasi penerus bangsa, oleh karenanya pendidikan mendapatkan perhatian khusus oleh pemerintah maupun masyarakat, 
terlepas apakah sekolah itu Negeri, Swasta, atau Yayasan ataupun yang lainnya tujuan sekolah adalah untuk membentuk karakter seseorang dan tempat menuntut ilmu.

Seiring dengan berkembangnya teknologi, sistem pendidikan pun mulai menyesuaikan dan memberikan kebijakan kepada anggota sekolah untuk bisa lebih memanfaatkan secara positif teknologi. Penggunaan teknologi pada pihak sekolahpun terhitung masih sangat minim terlebih dalam pemanfaatan dengan menggunakan sistem terkomputerisasi sangat jarang sekali. Padahal sekolah seharusnya menjadi tempat yang sudah bisa merasakan manfaat dari teknologi, baik dalam proses belajar mengajar maupun dalam kepengurusan data sekolah mencakup siswa dan data-data penting dalam suatu sekolah.

Dengan memanfaatkan teknologi, pekerjaan seorang karyawan sekolah akan lebih mudah dan terstruktur dengan rapi hanya dengan menerapkan sistem komputerisasi dalam bekerja, contohnya yang peneliti alami selama riset di Sekolah Dasar Islam Terpadu As-Sabiquun yaitu dalam data penerimaan siswa baru, memberikan nomor induk sekolah kepada siswa yang telah dinyatakan diterima oleh pihak sekolah sesuai dengan tahun angkatan dan merekap data siswa sebagai bukti laporan kepada pihak sekolah. Itulah yang mendorong peneliti untuk membuat suatu program penerimaan siswa baru yang diberi nama "sindikat" sistem informasi pendidikan terpadu.

Tujuannya adalah untuk merancang suatu program berbasis web dalam penerimaan siswa baru serta menerapkan sistem terkomputerisasi untuk mempermudah karyawan sekolah mendata setiap murid baru agar lebih efisien dalam waktu dan meminimalisasi kesalahan, memberikan data yang akurat dan tepat sesuai kebutuhan pihak sekolah. Bahasa pemrograman menurut Kadir [1] merupakan untaian kata-kata berupa instruksi atau perintahperintah yang biasanya terdiri dari banyak baris yang bisa dimengerti oleh komputer. Sedangkan menurut [2] "Database bisa dikatakan sebagai suatu kumpulan dari data yang tersimpan dalam tabel dan diatur atau diorganisasikan sehingga data tersebut bisa diambil atau dicari dengan mudah dan efisien".

Penerimaan merupakan suatu proses menganalisis persyaratan pekerjaan, mencari dan mengumpulkan calon atau kandidat yang memenuhi syarat sesuai kebutuhan, menurut Wijayanti [3]. Website menurut Abdulloh [4] merupakan kumpulan halaman yang menampilkan informasi data teks, data gambar diam atau gerak, data animasi, suara, video dan atau gabungan dari semuanya, baik yang bersifat statis maupun dinamis yang membentuk satu rangkaian bangunan yang saling terkait dimana masing-masing dihubungkan dengan jaringanjaringan halaman (hyperlink). Menurut Rusmawan [5] basis data dapat dipahami sebagai suatu kumpulan data terhubung yang disimpan secara bersama-sama pada suatu media, tanpa mengatap satu sama lain atau tidak perlu mengatap satu sama lain atau tidak perlu suatu kerangkapan data, data disimpan dengan cara-cara tertentu sehingga mudah untuk digunakan untuk menampilkan kembali, data dapat digunakan satu atau lebih program-program aplikasi secara optimal, data disimpan tanpa mengalami ketergantungan dengan program yang akan menggunakannya, data disimpan dengan sedemikian rupa sehingga proses penambahan, pengembalian, dan modifikasi data dapat dilakukan dengan mudah dan terkontrol. Dan masih menurut Rusmawan [5] menjelaskan bahwa "MySQL (My Structure Query Language) adalah suatu bahasa komputer yang mengikuti standar American National Standard Institute (ANSI), yaitu sebuah bahasa standar yang digunakan untuk mengakses dan melakukan manipulasi sistem database. Berdasarkan dari penjelasan tersebut, MySQL menggunakan bahasa SQL yang berfungsi dalam mengolah database.

\section{Metode Penelitian}

Metode yang digunakan adalah pada pengembangan perangkat lunak yaitu metode waterfall menurut Rosa dan Shalahuddin dalam harjunawati [6] dengan tahapan-tahapan sebagai berikut:1) Analisis Kebutuhan, tahap ini menjelaskan kebutuhan awal pengguna dalam sistem yang sedang berjalan. Pengguna membutuhkan aplikasi web untuk menampung data siswa baru dan memberikan nomor induk sesuai dengan tahun angkatan diterimanya seorang murid yang nantinya akan bersekolah di Sekolah Dasar Islam Terpadu As-Sabiquun. 2) Desain, dalam proses desain sistem, peneliti menjabarkannya dalam bentuk Entity Relationship Diagram (ERD) dan Logical Record Structure (LRS). Menurut Jogiyanto dalam Munif [7] Entity Relationship Diagram merupakan diagram teknik yang digunakan untuk memodelkan kebutuhan data dari suatu organisasi, untuk sistem analisis dalam tahap proyek pengembangan system. Sedang menurut Masturoh [8] Masing-masing tabel diidentifikasi dengan field-field yang 
memberikan ciri dan karakter untuk menginformasikan fungsi dari setiap tabel. Dan menurut Jariyah [9] Logical Record Structure (LRS) adalah representasi dari struktur record-record pada tabel-tabel yang terbentuk dari hasil antar himpunan entitas. Sedangkan dalam merancang programnya peneliti menggunakan Microsoft Visual Code sebagai text editor dengan database PhpMyAdmin yang berfungsi untuk mengelola database dengan menggunakan XAMPP. 3) Pembuatan Kode Program, setelah membuat rancangan desain, peneliti mentranslasikan rancangan desain dengan menggunakan Bahasa pemrograman yang variatif. 4) Implementasi dan Pengujian Unit, Peneliti menguji coba program untuk mengetahui apakah program sudah berjalan sesuai struktur navigasi yang sudah dibuat. 5) Pendukung atau Pemeliharaan, pada tahap ini, Peneliti melakukan pemeliharaan dan perbaikan program apabila program tersebut terdapat kesalahan atau adanya perubahan yang tidak terdeteksi pada tahap sebelumnya dengan mencoba memanfaatnya black box testing sebagai pengujian program. Menurut Rosa [10] black box testing adalah pengujian perangkat lunak dari segi spesifikasi fungsional tanpa menguji desain dan kode program

\section{Hasil dan Pembahasan \\ Analisis Kebutuhan}

Perancangan sistem informasi berbasis web "sindikat" pada dasarnya adalah untuk penerimaan siswa baru yang ingin menggunakan sistem terkomputerisasi dalam pengelolaannya, sehingga data yang dikelola lebih tertata dan aman dalam penyimpanannya, melihat di tempat yang penulis riset belum menggunakan sistem terkomputerisasi maka penulis mencoba untuk merancang web untuk mempermudah pendataan siswa. Adapun prosedur penerimaan siswa baru pada web "sindikat" adalah 1) Prosedur pendaftaran member dengan kegiatan seperti berikut: pihak orang tua mengunjungi website "sindikat" yang mana pendaftar akan langsung di bawa pada halaman utama yaitu form login. Pihak pendaftar yang belum mempunyai account bisa langsung memilih registrasi dan membuat account untuk mendaftarkan anaknya. 2) Prosedur pendaftaran siswa baru dengan kegiatan seperti berikut: setelah berhasil mempunyai account maka selanjutnya adalah pihak pendaftar bisa langsung masuk di halaman login yang sudah disediakan, kemudian memilih menu daftar siswa dan mengisi seluruh data siswa dengan sebenar-benarnya sesuai dengan kebutuhhan yang sudah ditentukan oleh pihak sekolah. Setelah selesai mengisi data siswa, pihak pendaftar bisa langsung mencetak formulir pendaftaran dan mengecek ulang apakah data yang sudah di masukkan benar apa masih ada kesalahan,setelah dirasa benar semua maka pihak orang tua atau wali siswa bisa langsung memberikan tanda tangan bahwa data yang diberikan benar adanya.

\section{Rancangan}

Pada kegiatan rancangan peneliti membagi menjadi beberapa tahapan rancangan, yaitu merancang database yang direpresentasikan dengan model Entity Relationship Diagram dan Logical Record Structure. Sedangkan untuk rancangan program berbasis web nya direpresentasikan dengan alur navigasi. Untuk perancangan database pada Sistem Informasi Penerimaan Siswa Baru menghasilkan database yang terdiri dari beberapa tabel. Diantaranya adalah Tabel Access, Tabel Admin, Tabel Graduate, Tabel Job, Tabel Father, Tabel Mother, Tabel Religion, Tabel State, Tabel Student, Tabel Teacher, Tabel Tranportation, Tabel UserAccess_Menu, Tabel User_Menu, Tabel User_Sub_Menu, Tabel User dan Tabel Web_Setting. Pemetaan tabel-tabel dan hubungan antar tabel tersebut dalam rancangan database pada sistem informasi penerimaan siswa pada Sekolah Dasar Islam Terpadu As-Sabiquun direpresentasikan dalam Entity Relationship Diagram, seperti gambar dibawah ini. 


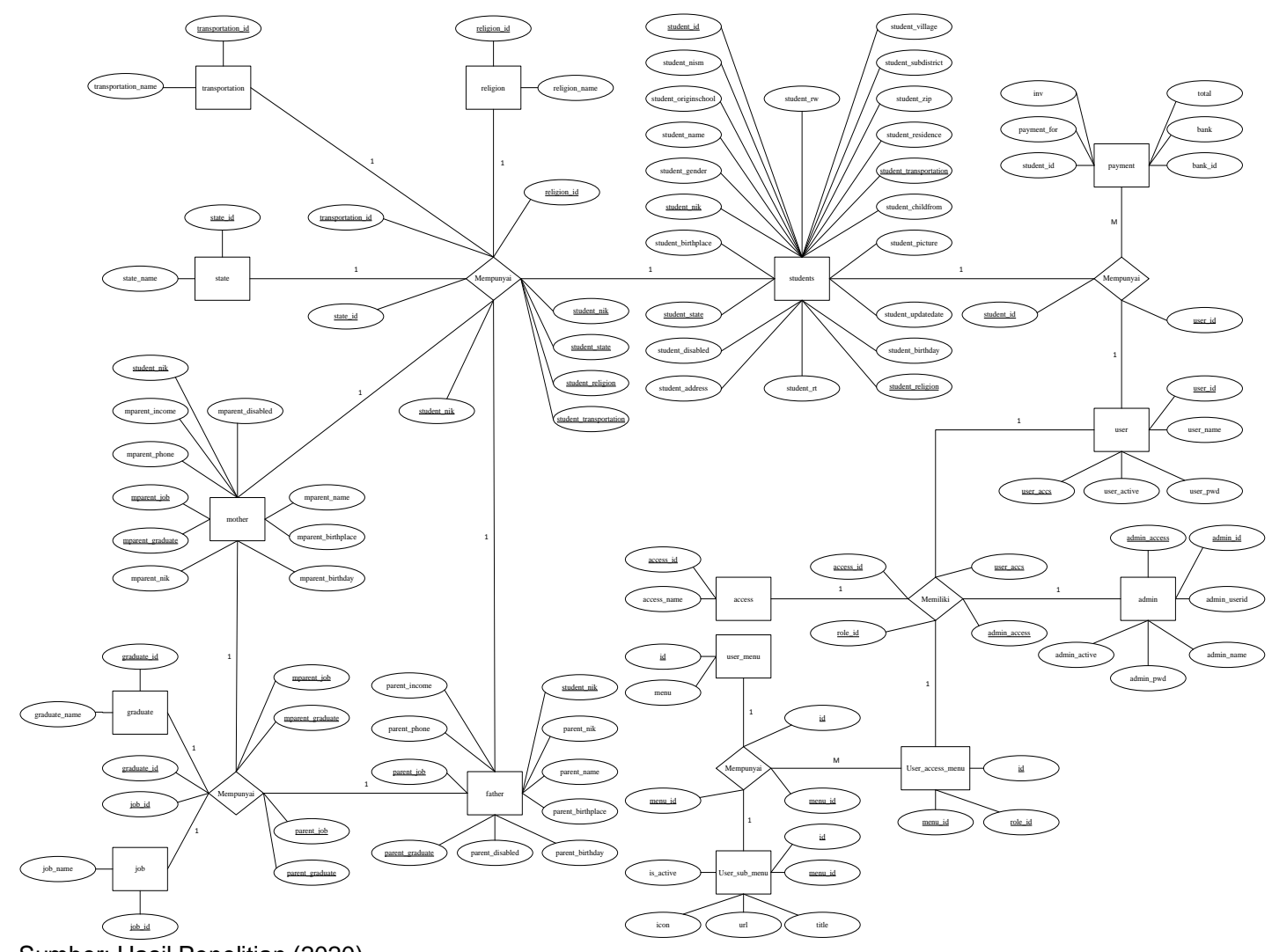

Sumber: Hasil Penelitian (2020)

Gambar 1. Entity Relationship Diagram Sistem Informasi Penerimaan Siswa

Gambar Entity Relationship Diagram di atas memperlihatkan adanya relasi antar tabeltabel yang dirancang seperti yang sudah disebutkan dalam uraian di atas, yang merupakan bagian dari perancangan Database dalam Sistem Informasi Penerimaan Siswa Baru pada SDIT As-Sabiquun yang sebelumnya pada sistem berjalan belum memiliki database. Berikut gambar 2 merupakan gambaran Logical Record Structure (LRS) dari Sistem Informasi Penerimaan Siswa

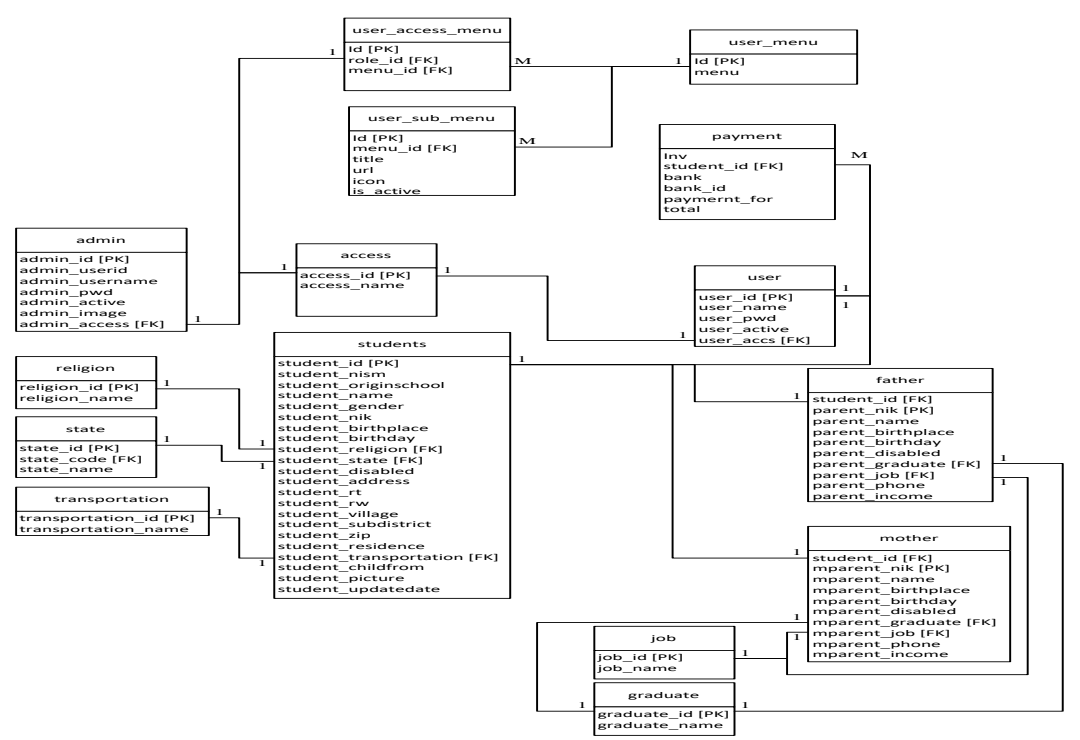

Sumber: Hasil Penelitian (2020)

Gambar 2. Logical Record Structure dari Sistem Informasi Penerimaan Siswa

Berdasarkan pemetaan dari Entity Relationship Diagram, maka tabel-tabel yang sudah dirancang ditransformasikan ke dalam bentuk Logical Record Structure (seperti pada gambar 
2), yang fungsinya adalah menentukan kardinalitas antar tabel, jumlah tabel dan Foreign Key (FK).

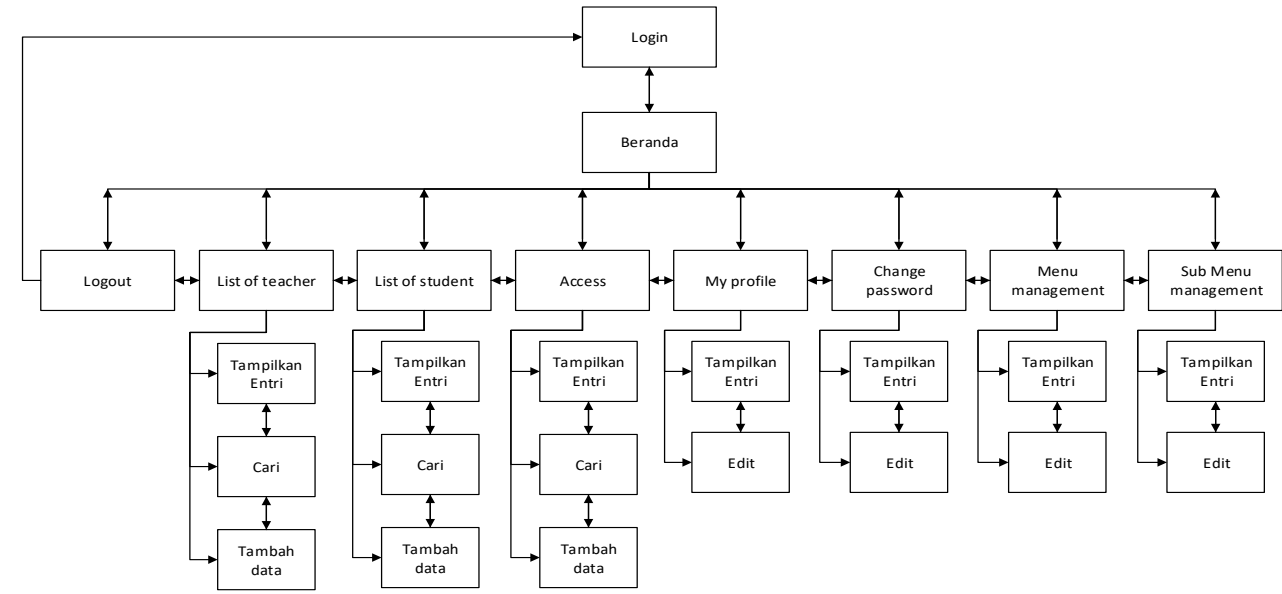

Sumber: Hasil Penelitian (2020)

Gambar 3. Struktur navigasi halaman Admin

Gambar 3 merupakan navigasi bagi admin, yang memperlihatkan alur penggunaan webnya. Dan dari 2 gambar tadi dapat kita lihat ada yang membedakan antara pengguna super admin dan admin. Yang dimaksud super admin adalah pemilik yayasan, sedangkan admin adalah pengelola webnya. Sehingga hak akses terhadap menu-menu nya pun dapat terlihat jelas.

\section{Struktur Navigasi Halaman Teacher}

Gambar 4 merupakan navigasi bagi guru (teacher), yang dapat menjelaskan tentang hak akses yang dapat digunakan oleh para guru Sekolah Islam As Sabiquun. Dimana guru dapat mengakses dengan cara login terlebih dahulu lalu berikutnya dapat mengakses menu Myprofile, Change Password, Student dan Logout.

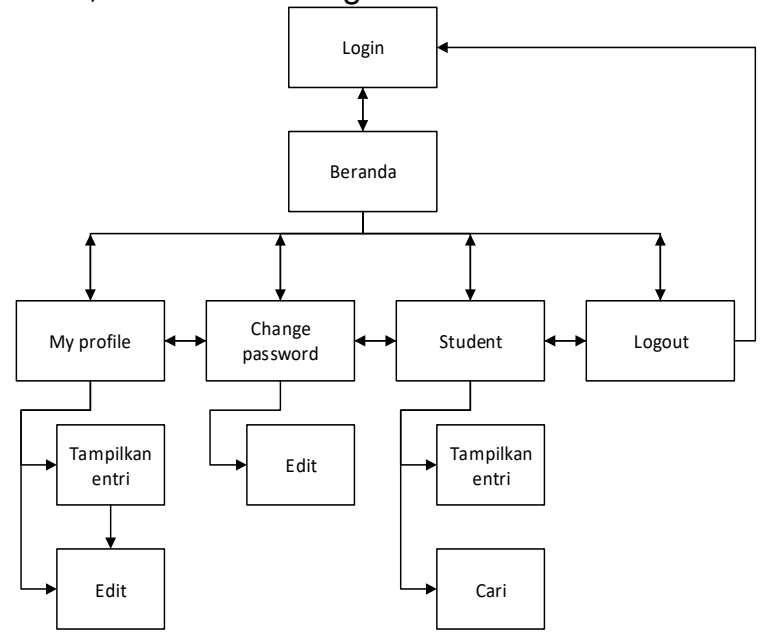

Sumber: Hasil Penelitian (2020)

Gambar 4 Struktur navigasi halaman teacher

\section{Struktur Navigasi Halaman Student}

Gambar 5 merupakan navigasi bagi siswa (student), yang dapat menjelaskan tentang hak akses yang dapat digunakan oleh para siswa Sekolah Islam As Sabiquun. Dimana siswa dapat mengakses dengan cara login terlebih dahulu lalu berikutnya dapat mengakses Mydataprofile, Change Password, dan Logout. 


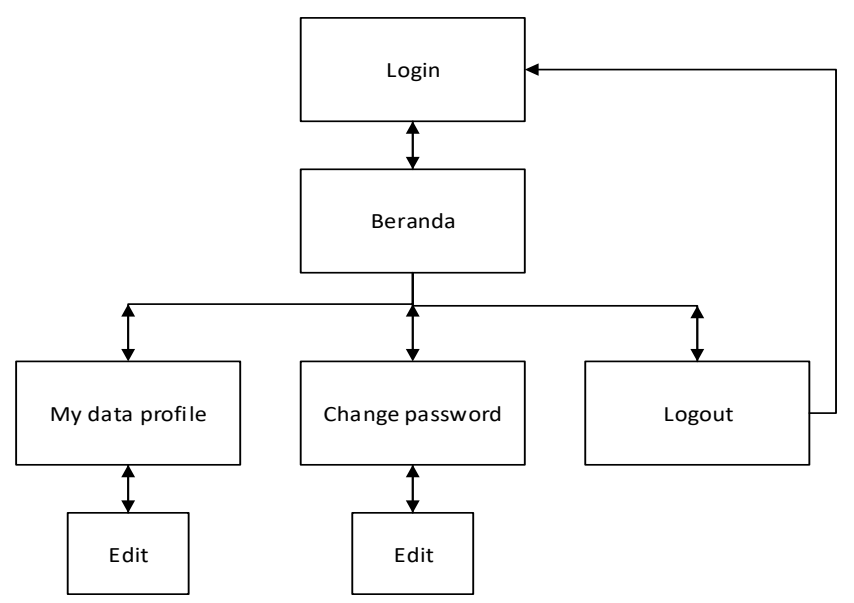

Sumber:Hasil Penelitian (2020)

Gambar 5. Struktur navigasi halaman student

\section{Struktur Navigasi Halaman Pengunjung}

Gambar 6 merupakan navigasi bagi pengunjung, dimana akses yang diperbolehkan bagi pengunjung web Sekolah Islam As Sabiquun adalah melihat halaman beranda kemudian dapat melakukan Registrasi, mengakses data alamat dan My account dan login jika memang sudah melakukan registrasi.

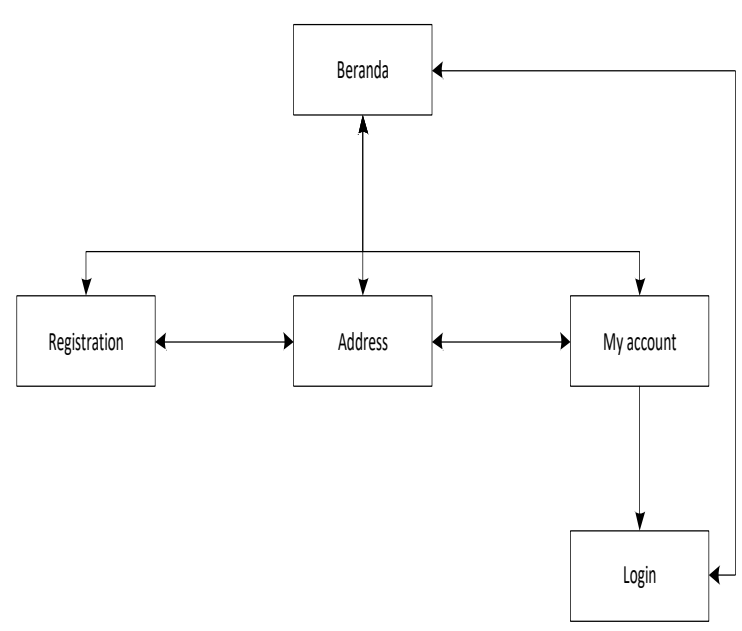

Sumber: Hasil Penelitian (2020)

Gambar 6. Struktur navigasi halaman pengunjung

\section{Implementasi}

Implementasi rancangan antar muka pada Perancangan Sistem Informasi Penerimaan Siswa Baru Berbasis Web, diantaranya adalah:

\section{Halaman Index (Beranda)}


Tabel. 1 Tampilan Antarmuka

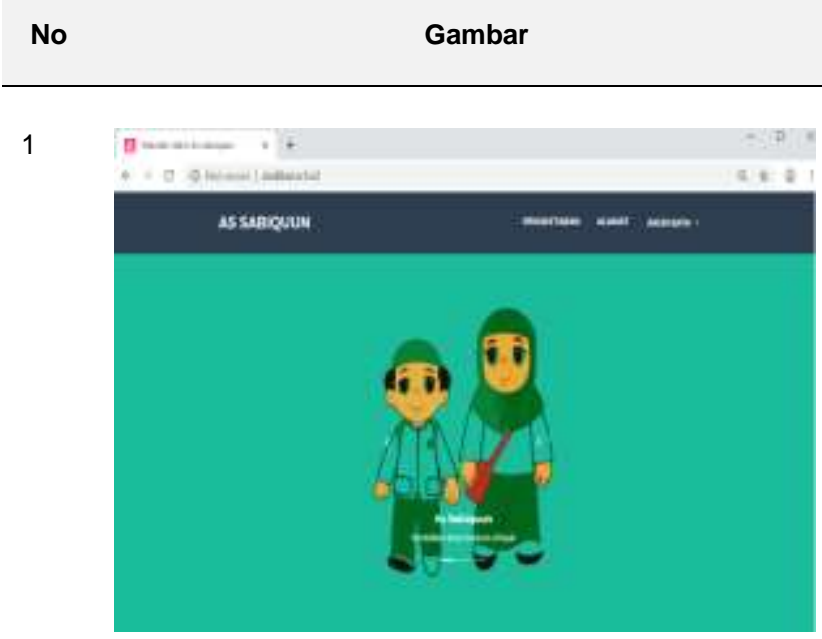

\section{Keterangan}

Merupakan implementasi dari rancangan sistem informasi penerimaan siswa baru berbasis web Pada Sekolah Islam As Sabiquun. Pengunjung web dapat melihat tampilan pada halaman index web yang terdiri dari menu Pendaftaran, Alamat dan Akun saya. Dari menu-menu yang disajikan, pengunjung dapat memilih sesuai dengan tujuannya berkunjung ke web Sekolah Islam As Sabiquun.

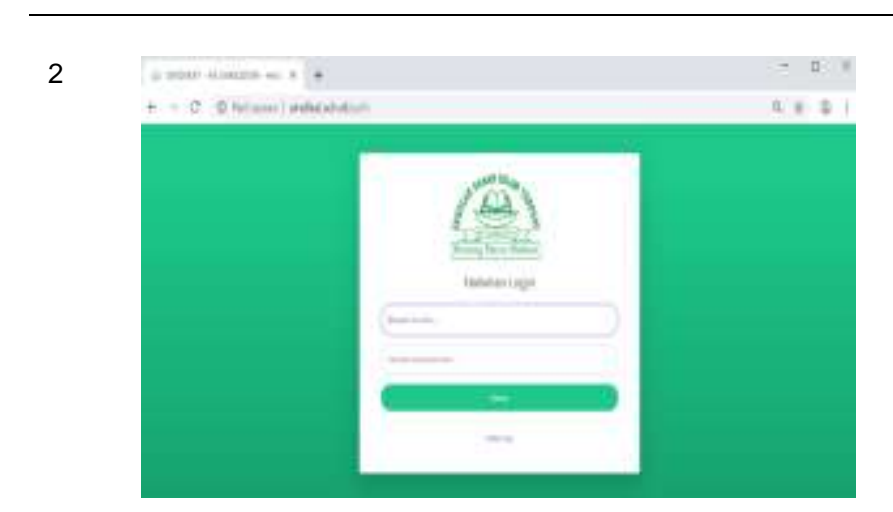

Pada implementasi halaman login diperuntukkan bagi pengguna yang sudah memiliki akses ke web Sekolah Islam As Sabiquun. Diantaranya super admin, admin, guru, murid dan oran tua dari calon murid yang akan mendaftar ke sekolah Islam As Sabiquun, yang sebelumnya sudah melakukan registrasi terlebih dahulu.

3

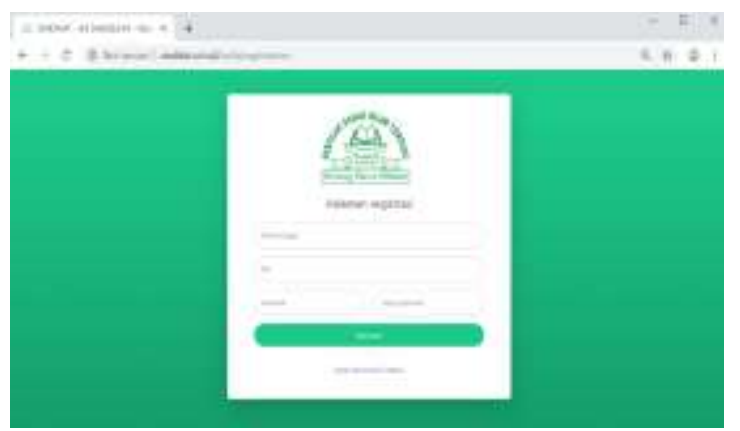

4

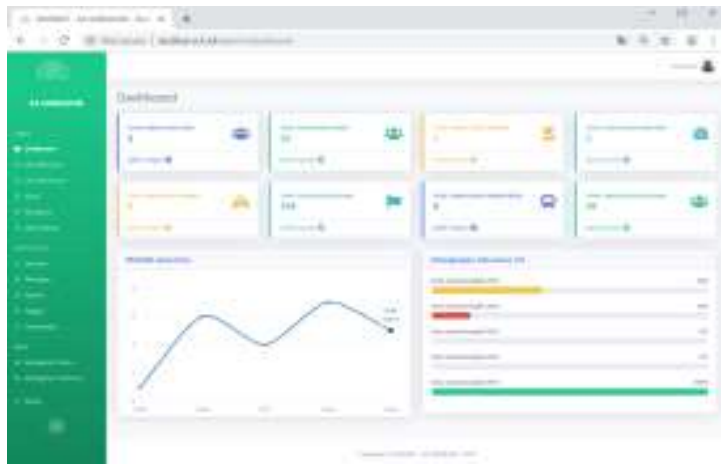

Tampilan web yang diperuntukkan bagi pihak pendaftar yang belum mempunyai account, dimana pihak pendaftar, yang mungkin diwakili oleh orang tua calon siswa bisa langsung memilih registrasi dan membuat account untuk mendaftarkan anaknya.
Implementasi dari rancangan web tentang tampilan dari halaman dashboard super admin dan admin, yang terdiri dari beberapa menu pilihan diantaranya adalah menu informasi tentang total jumalh data guru, total jumlah data siswa, total jumlah tamatan, total jumlah data pekerjaan, total jumlah data Negara, total jumlah data transportasi dan total jumlah data pengguna. Yang sekaligus ditampilkan dengan grafiknya. 


\section{Pengujian Unit}

Pengujian yang dilakukan terhadap program yang dibuat menggunakan blackbox testing yang focus terhadap proses masukan dan keluaran program untuk mengetahui kekurangan dari program dan program berjalan sesuai dengan yang diharapkan. Pengujian dilakukan pada beberapa kegiatan sebagai berikut:

\section{Pengujian Terhadap Halaman Login}

Pengujian pertama dilakukan terhadap halaman login, tabel 2 menjelasakan secara detail hasil pengujian yang telah dilakukan.

Tabel 2. Hasil pengujian black box testing halaman login

\begin{tabular}{|c|c|c|c|c|c|}
\hline No. & Skenario pengujian & Test case & $\begin{array}{ll}\begin{array}{l}\text { Hasil } \\
\text { diharapkan }\end{array} & \text { yang } \\
\end{array}$ & $\begin{array}{l}\text { Hasil } \\
\text { pengujian }\end{array}$ & $\begin{array}{l}\text { Kesimpula } \\
\mathrm{n}\end{array}$ \\
\hline 1 & $\begin{array}{lr}\text { Tidak menigisi } & \text { di semua } \\
\text { kolom-kolom yang } & \text { di } \\
\text { sediakan kemudian } & \text { klik } \\
\text { tombol register account } & \end{array}$ & $\begin{array}{l}\text { Full name: (Kosong) } \\
\text { Nik: (kosong) } \\
\text { Password: (kosong) } \\
\text { Repeat password: } \\
\text { (kosong) } \\
\end{array}$ & $\begin{array}{l}\text { Sistem akan menolak } \\
\text { akses user dan } \\
\text { menampilkan pesan } \\
\text { "The ID and password } \\
\text { field is required" }\end{array}$ & $\begin{array}{l}\text { Sesuai } \\
\text { harapan }\end{array}$ & Valid \\
\hline 2 & $\begin{array}{l}\text { Mengisi semua kolom-kolom } \\
\text { yang ada tetapi kolom nik } \\
\text { sudah ada di dalam database } \\
\text { kemudian klik tombol register } \\
\text { account }\end{array}$ & $\begin{array}{l}\text { Full name: Johan } \\
\text { Nik: } \\
\text { 1234567890123456 } \\
\text { Password: } 1234 \\
\text { Repeat password: } \\
1234\end{array}$ & $\begin{array}{l}\text { Sistem akan menolak } \\
\text { akses user dan } \\
\text { menampilkan pesan } \\
\text { "The password field is } \\
\text { required" }\end{array}$ & $\begin{array}{c}\text { Sesuai } \\
\text { harapan }\end{array}$ & Valid \\
\hline 3 & $\begin{array}{l}\text { Mengisi semua kolom-kolom } \\
\text { yang ada dan kolom nik } \\
\text { belum terdaftar di dalam } \\
\text { database tetapi password } \\
\text { dan repeat password tidak } \\
\text { sama kemudian klik tombol } \\
\text { register account }\end{array}$ & $\begin{array}{l}\text { Full name: Johan } \\
\text { Nik: } \\
1234567890123456 \\
\text { Password: } 1234 \\
\text { Repeat password: } \\
12345 \text { }\end{array}$ & $\begin{array}{l}\text { Sistem akan menolak } \\
\text { akses user dan } \\
\text { menampilkan pesan } \\
\text { "Incorrect id or } \\
\text { password" }\end{array}$ & $\begin{array}{c}\text { Sesuai } \\
\text { harapan }\end{array}$ & Valid \\
\hline 4 & $\begin{array}{l}\text { Mengisi semua kolom-kolom } \\
\text { yang ada dan kolom nik } \\
\text { belum terdaftar di dalam } \\
\text { database password dan } \\
\text { repeat password sama } \\
\text { kemudian klik tombol register } \\
\text { account }\end{array}$ & $\begin{array}{l}\text { Full name: Johan } \\
\text { Nik: } \\
\text { 1234567890123456 } \\
\text { Password: } 1234 \\
\text { Repeat password: } \\
1234 \quad\end{array}$ & 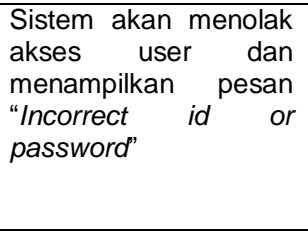 & $\begin{array}{c}\text { Sesuai } \\
\text { harapan }\end{array}$ & Valid \\
\hline
\end{tabular}

\section{Pengujian Halaman Registration}

Pengujian kedua dilakukan terhadap halaman login, tabel 3 menjelasakan secara detail hasil pengujian yang telah dilakukan.

Tabel 3. Hasil pengujian black box testing halaman registration

\begin{tabular}{|c|c|c|c|c|c|}
\hline No. & Skenario pengujian & Test case & Hasil yang diharapkan & $\begin{array}{c}\text { Hasil } \\
\text { penquilian }\end{array}$ & Kesimpulan \\
\hline 1 & $\begin{array}{lr}\text { Tidak menigisi } \text { di semua } \\
\text { kolom-kolom yang } & \text { di } \\
\text { sediakan kemudian klik } \\
\text { tombol register account }\end{array}$ & $\begin{array}{l}\text { Full name: (Kosong) } \\
\text { Nik: (kosong) } \\
\text { Password: (kosong) } \\
\text { Repeat password: } \\
\text { (kosong) }\end{array}$ & $\begin{array}{lr}\text { Sistem } & \text { akan } \\
\text { memberitahukan } & \text { agar } \\
\text { semua kolom-kolom yang } \\
\text { ada harus disi }\end{array}$ & $\begin{array}{l}\text { Sesuai } \\
\text { harapan }\end{array}$ & Valid \\
\hline 2 & $\begin{array}{l}\text { Mengisi semua kolom-kolom } \\
\text { yang ada tetapi kolom nik } \\
\text { sudah ada di dalam database } \\
\text { kemudian klik tombol register } \\
\text { account }\end{array}$ & $\begin{array}{l}\text { Full name: Johan } \\
\text { Nik: } \\
\text { 1234567890123456 } \\
\text { Password: } 1234 \\
\text { Repeat password: } \\
1234\end{array}$ & $\begin{array}{lr}\text { Sistem } & \text { akan } \\
\text { memberitahukan } & \text { pesan } \\
\text { "The Nik field already } \\
\text { exists" }\end{array}$ & $\begin{array}{l}\text { Sesuai } \\
\text { harapan }\end{array}$ & Valid \\
\hline 3 & $\begin{array}{l}\text { Mengisi semua kolom-kolom } \\
\text { yang ada dan kolom nik } \\
\text { belum terdaftar di dalam } \\
\text { database tetapi password } \\
\text { dan repeat password tidak } \\
\text { sama kemudian klik tombol } \\
\text { register account }\end{array}$ & $\begin{array}{l}\text { Full name: Johan } \\
\text { Nik: } \\
\text { 1234567890123456 } \\
\text { Password: } 1234 \\
\text { Repeat password: } \\
12345\end{array}$ & $\begin{array}{l}\text { Sistem akan } \\
\text { memberitahukan pesan } \\
\text { "The password field does } \\
\text { not match the repeat } \\
\text { password" }\end{array}$ & $\begin{array}{l}\text { Sesuai } \\
\text { harapan }\end{array}$ & Valid \\
\hline 4 & $\begin{array}{l}\text { Mengisi semua kolom-kolom } \\
\text { yang ada dan kolom nik } \\
\text { belum terdaftar di dalam }\end{array}$ & $\begin{array}{l}\text { Full name: Johan } \\
\text { Nik: } \\
1234567890123456\end{array}$ & $\begin{array}{l}\text { Sistem menerima data } \\
\text { inputan dan kemudian } \\
\text { menampilkan form login }\end{array}$ & $\begin{array}{l}\text { Sesuai } \\
\text { harapan }\end{array}$ & Valid \\
\hline
\end{tabular}




\begin{tabular}{|c|c|c|c|c|c|}
\hline No. & Skenario pengujian & Test case & Hasil yang diharapkan & $\begin{array}{c}\text { Hasil } \\
\text { pengujian }\end{array}$ & Kesimpulan \\
\hline & $\begin{array}{l}\text { database password dan } \\
\text { repeat password sama } \\
\text { kemudian klik tombol register } \\
\text { account }\end{array}$ & $\begin{array}{l}\text { Password: } 1234 \\
\text { Repeat password: } \\
1234\end{array}$ & & & \\
\hline
\end{tabular}

\section{Pengujian Halaman List Of Teacher}

Pengujian ketiga dilakukan terhadap halaman login, tabel 4 menjelasakan secara detail hasil pengujian yang telah dilakukan.

Tabel 4. Hasil pengujian black box testing halaman list of teacher

\begin{tabular}{|c|c|c|c|c|c|}
\hline No. & $\begin{array}{l}\text { Skenario } \\
\text { pengujian }\end{array}$ & Test case & $\begin{array}{l}\text { Hasil yang } \\
\text { diharapkan }\end{array}$ & $\begin{array}{c}\text { Hasil } \\
\text { pengujian }\end{array}$ & Kesimpulan \\
\hline 1. & $\begin{array}{l}\text { Tidak menigisi di } \\
\text { semua kolom- } \\
\text { kolom yang di } \\
\text { sediakan } \\
\text { kemudian klik } \\
\text { tombol save }\end{array}$ & $\begin{array}{c}\text { Name: (kosong) } \\
\text { Nik: (kosong) } \\
\text { Phone: (kosong) } \\
\text { Birthday: (kosong) } \\
\text { Password: (kosong) } \\
\text { Repeat password: } \\
\text { (kosong) } \\
\text { Address: (kosong) } \\
\text { User active: (tidak } \\
\text { di select) }\end{array}$ & $\begin{array}{c}\text { Sistem akan } \\
\text { memberitahukan agar } \\
\text { semua kolom-kolom } \\
\text { yang ada harus disi }\end{array}$ & Sesuai harapan & Valid \\
\hline 2 & $\begin{array}{l}\text { Tidak menigisi di } \\
\text { salah satu kolom } \\
\text { kemudian klik } \\
\text { tombol save }\end{array}$ & $\begin{array}{c}\text { Name: Bedegul } \\
\text { Nik: (kosong) } \\
\text { Phone: } 12345678 \\
\text { Birthday: } \\
\text { 02/26/1973 } \\
\text { Password: } 1234 \\
\text { Repeat password: } \\
\text { 1234 } \\
\text { Address: EJIP } \\
\text { User active: (active) }\end{array}$ & $\begin{array}{c}\text { Sistem akan } \\
\text { memberitahukan agar } \\
\text { kolom kosong harus } \\
\text { disi }\end{array}$ & Sesuai harapan & Valid \\
\hline
\end{tabular}

\section{Kesimpulan}

Sekolah As-Sabiquun sangat membutuhkan adanya sistem informasi yang menunjang dalam proses penerimaan siswa baru. Dengan demikian sudah sewajarnya jika perombakan terjadi pada sistem sekolah dengan menggunakan teknologi terkomputerisasi salah satunya adalah untuk masalah penerimaan siswa baru pada sekolah As-Sabiquun. Dan kesimpulan yang dapat diambil dengan adanya aplikasi berbasis web ini diharapkan pada pencatatan data siswa baru dapat mengurangi kesalahan pada pihak orang tua pendaftar sebagai pemberi informasi dan juga pada pihak sekolah selaku penginput data siswa karena pada sistem ini pihak orang tua pendaftar dapat mengisi formulirnya di rumah dengan hanya mengunjungi web yang sudah disediakan oleh pihak sekolah dan mengisi seluruh data formulir dengan cermat sesuai kebutuhan yang sudah disediakan. Program 'sindikat" ini khususnya untuk kegiatan penerimaan siswa baru, lebih mudah dalam pengelolaannya seperti input data, hapus data dan update data. Media penyimpanan yang menggunakan database akan menjamin lebih aman dan dapat menyimpan data dalam jumlah banyak. Untuk mempercantik tampilan web agar terlihat lebih dinamis peneliti menggunakan beberapa framework berikut, antara lain: CSS (Cascading Style Sheet), Bootstrap, Cl (Code Igniter) dengan database MySQL. Untuk mengantisipasi kerusakan sistem maupun perangkat keras, maka sebaiknya dalam jangka waktu tertentu dilakukan backup data dari database yang dibuat ke dalam penyimpanan luar baik berupa harddisk, CD dan lain sebagainya. Bagi pihak orang tua diharapkan untuk selalu mengingat password untuk masuk ke situs web karena pada sistem ini belum tersedia kolom reset password. Dan inilah yang nantinya akan dikembangkan pada penelitian selanjutnya.

\section{Referensi}

[1] A. Kadir, Dasar Logika Pemrograman Komputer. Bandung: PT Elex Media Komputindo, 2017.

[2] B. Haqi, Membuat Aplikasi Antrian Dengan Java NetBeans dan MySQL. Bandung: PT Elex Media Komputindo, 2017. 
[3] J. K. A. Diah Wijayanti, ratih Dwi asworowati, "Sistem Informasi Penerimaan Pengemudi Berbasis Web Dengan Metode Prototype : Studi kasus PT. Dinamika Makmur Sentosa Cikarang," vol. 3, 2018.

[4] R. Abdulloh, 7 in 1 Pemrograman Web Untuk Pemula. Elex Media Komputindo, 2018.

[5] U. Rusmawan, Teknik penulisan tugas akkhir dan skripsi pemerograman. 2019.

[6] S. Harjunawati, "Sistem Informasi Akuntansi Penjualan Berbasis Waterfall Model Untuk Perusahaan Dagang," Indones. J. Comput. Inf. Technol., 2017, doi: 10.1016/01689002(90)90652-M.

[7] A. Munif, D. Wijayanti, and E. Haryadi, "Sistem Informasi Penyewaan Rumah Kontrakan Berbasis Web Dengan Menggunakan Metode Prototype," J. Interkom, vol. 15, no. 1, 2020.

[8] D. Wijayanti and A. Prasetyo, "Sistem Informasi Akademik Berbasis Web Menggunakan Model Waterfall Pada SMK ITENAS Karawang," J. Inform., vol. 6, no. 1, pp. 62-68, 2019.

[9] F. A. JARIYAH, "SISTEM E-RECRUITMENT KARYAWAN BERBASIS WEB PADA PT. JASA SWADAYA UTAMA (JAYATAMA)."

[10] M. S. A.S, Rosa, Rekayasa Perangkat Lunak, Terstruktur dan Berorientasi Objek. Bandung: Informatika, 2013. 